\title{
Die sogenannte Praefatio Hieronymi in libro psalmorum
}

\author{
Barbara Villani
}

Viele Prologtexte des Origenes und Eusebius finden sich in einer eigentümlichen Sammlung in lateinischer Sprache, welche unter der Bezeichnung Praefatio Hieronymi in libro psalmorum überliefert wurde und in den Textzeugen teilweise dem lateinischen Kirchenvater zugewiesen wird. Man könnte sagen, dass es sich um eine Art lateinische Katene handelt, obwohl sie lange nicht als solche erkannt wurde. Die Schrift ist relativ gut überliefert und wurde im 17. und 18. Jahrhundert in mehreren Ausgaben abgedruckt. ${ }^{1}$

Die Autorschaft des Hieronymus war in der Forschung jedoch schon früh umstritten. Louis Ferrand, der erste Herausgeber des Textes, sprach sich gegen die Authentizität aus und hielt den Verfasser für den Kompilator des pseudohieronymianischen Breviarium in Psalmos. ${ }^{2}$ Jean-Baptiste Cotelier bestritt diese Identifizierung mit dem Kompilator des Breviarium, bezweifelte aber ebenfalls die Autorschaft des Hieronymus. ${ }^{3}$ Der Mauriner Jean Martianay, dessen Edition in der Patrologia Latina abgedruckt ist, hielt die Praefatio für ein Werk des Eusebius, welches von einem unbekannten Übersetzer in äußerst schlechtes Latein übersetzt wurde. In einer Anmerkung spricht er sich dafür aus, dass die Übersetzung mit Absicht untreu und die Reihenfolge der einzelnen Passagen etwas vertauscht worden sei, damit die eusebianische Autorschaft nicht so deutlich erkannt würde. ${ }^{4}$

1 Dazu Mercati, Osservazioni, 74f.

2 Vgl. Ferrand, Liber Psalmorum, 915: Haec Praefatio Hieronymianum stilum non sapit, adeoque doctissimo Presbytero abjudicanda videtur.

3 Vgl. Cotelier, Ecclesiae Graecae Monumenta III, Sp. 585f.: Jam ad Psalterium quod attinet, lubet emendatione, distinctione, luce donare insigne comma Praefationis in Psalmos, quam anno superiori ex Codice Theodulfi Memmiano edendam curavit optimus doctissimusque Ferrandus noster, quaeque ratione styli habita nec Hieronymi, nec Hieronymiani illius consarcinatoris esse videtur.

4 Das Vorwort Martianays findet man in PL 26,1299f. abgedruckt: Cujus porro fuerit, etsi non omnino mihi constet, vix tamen dubito quin hic prologus Eusebio Caesariensi sit ascribendus: pars enim non minima de ejusdem hypothesibus in Psalterio derivata, id nobis renuntiare videtur. Sed quisquis praefationem Latinitate donavit, vix primis fuit imbutus litteris, ut in Latinum non Latine eam verteret. Siehe auch 1301f., Anm. c zur absichtlichen Vertauschung der Reihenfolge: At qui Eusebium in hoc prologo per pannos et segmenta Latinis tradit, ordinem Hypothese $\tilde{\omega} v$ (sic) subvertere studuit, ne furtum agnosceremus. Vgl. dazu Mercati, Osservazioni, 80. 
Giovanni Mercati hat sich ausführlicher mit dem Text beschäftigt ${ }^{5}$ und kam $\mathrm{zu}$ dem Schluss, dass es sich nicht um ein Vorwort eines einzigen Autors handeln könne, sondern vielmehr um eine sehr wörtliche lateinische Übersetzung von aus verschiedenen Autoren zusammengesetzten griechischen Einleitungstexten, wie sie in Katenen zu finden sind. Vermutlich sei sie auch im Vergleich zur griechischen Vorlage unvollständig. ${ }^{6}$ Obwohl er das Problem der Übersetzerschaft nicht weiter erörtert, geht er davon aus, dass es nicht Hieronymus selbst gewesen sei, der den Text übersetzt habe, sondern ein Pseudo-Hieronymus. ${ }^{7}$ Der Stil der Übersetzung scheint einer Autorschaft des Hieronymus deutlich zu widersprechen, so dass auch ich mich Mercatis Meinung anschließen und von einem unbekannten Kompilator und Übersetzer ausgehen möchte. Ob dieser bereits in der griechischen Vorlage die Zusammenstellung der verschiedenen Passagen vorgefunden hatte oder selbst eine Auswahl getroffen hat, bleibt dahingestellt.

Die Praefatio wurde zahlreichen Bibel- und Psalterausgaben vorangestellt. ${ }^{8}$ Mercati hat drei Linien der Überlieferung nachgezeichnet. So hat der westgotische Gelehrte Theodulf von Orléans ${ }^{9}$ das Vorwort in den Handschriften seiner Bibelrezension an den Anfang gesetzt, dort meist unter dem Namen des Hieronymus. Da sich dort oft Texte spanischer Herkunft nachweisen lassen, liegt es nahe, die Vorlage in einer spanischen Handschrift des 7./8. Jahrhunderts zu vermuten.

Einen weiteren Überlieferungsstrang repräsentieren zwei jüngere Bibelhandschriften, welche den Hirten des Hermas beinhalten. Im ersten Textzeugen ${ }^{10}$ befindet sich die Praefatio nicht in unmittelbarer Nähe des Psalters, sondern direkt vor dem Hirten des Hermas, in der zweiten Handschrift ${ }^{11}$ dagegen ist sie mit dem Psalter verbunden. Dies weist darauf hin, dass der Text wohl nicht nur in Zusammenhang mit den Psalmen überliefert wurde, sondern auch als eigenständige Schrift galt.

In einer dritten Überlieferungslinie schließlich schließt sich die Praefatio einer kleinen Sammlung von Texten, die hauptsächlich den Psalter thematisieren, an: Es handelt sich um Brief 30 zu Psalm 118 und Brief 28 zum Diapsalma des Hieronymus,

5 Vgl. Mercati, Osservazioni, 74-116.

6 Vgl. Mercati, Osservazioni, 87f. Seiner Meinung nach handelt es sich bei der Vorlage um ein Vorwort einer griechischen Katene, in der sich möglicherweise ausschließlich Origenes und Euseb abwechseln.

7 So ordnet er die Praefatio im Register unter Pseudo-Hieronymus ein. Vgl. Mercati, Osservazioni, 166.

8 Vgl. Mercati, Osservazioni, 75f.

9 Er war Bischof von Orléans und lebte von 750/60-821. Um 800 fertigte er eine eigene Revision der Vulgata von Hieronymus an.

10 Vind. theol. lat. 1217 (1434).

11 Dresd. A 47 (15. Jh.). 
eine Predigt des Augustinus über die Psalmen sowie Brief 120, wiederum von Hieronymus.

Mercati hat den in acht Passagen unterteilten Text mit griechisch erhaltenen Exzerpten verglichen und sechs Entsprechungen gefunden. Fünf Texte können eindeutig Origenes oder Euseb zugewiesen werden. Ein kurzer lateinischer Text (De asterisco et obelo) lässt sich aufgrund von Parallelen zu anderen Stellen auf Origenes zurückführen. 